\title{
DEPARTMENTAL INITITATIVES TO ADDRESS EATING DISORDERS
}

\section{Beverley Raphael \\ Director, Centre for Mental Health}

NSW Health is taking up the challenge to improve pathways to care for children and adolescents who exhibit the earliest symptoms of eating disorders. The aim will be to improve detection and strengthen local networks of professionals who have skills to implement effective early intervention, including those who can offer appropriate specialist child and adolescent mental health support. A sum of $\$ 100,000$ has been allocated to the Department of Psychological Medicine at the New Children's Hospital at Westmead to develop an effective early intervention model for identifying and treating children and young people with eating disorders.

Expansion of a successful shared-care pilot project involving general practitioners and specialist mental health services in Central Sydney Area has also been funded. This program includes a training component for general practitioners that is expected to equip them with skills to detect eating disorders earlier and to intervene more effectively. In partnership with the former Ministerial Advisory Committee on Body Image and Disordered Eating, the Centre for Mental Health, NSW Health Department, convened workshops in mid-1998 involving several groups which provide support for people with eating disorders and their families. NSW Health is collaborating with the NSW Department of Education and Training in the development of the School-Link Program. The current focus of that program is on the prevention and early detection of depression in adolescents; however, the inclusion of components to teach positive coping and life skills has broader implications for mental health promotion.

The Centre for Mental Health and the Health Services Policy Branch are also assisting the Statewide Services Development Branch of the NSW Health Department in a project to develop a plan to provide services for people in NSW who have eating disorders. Consultants are currently working on a comprehensive service model that incorporates the full spectrum of care, from prevention and early intervention through to treatment for people with the most severe and complex problems. The process includes wide consultation with professionals, consumers and carers.

\section{Editor's note:}

The NSW Ministerial Advisory Committee on Body Image and Disordered Eating was formed in April 1997 on a recommendation of the Summit on Body Image and Eating Disorders held in Sydney in August 1996. The Summit was held in response to growing concern about health problems associated with disordered eating among young women, adolescents and children. It focused particularly on the effect of the media, fashion trends and other social pressures on women's body image and the relationship between those factors and such eating disorders as anorexia nervosa and bulimia nervosa. Following the release of the report from the Summit, the Minister announced the formation of an intersectoral Ministerial Advisory Committee to further examine the issues identified at the forum and to report back with recommendations for addressing those issues. The primary focus of the committee was on preventing disturbed body image and disordered eating.

\section{DENTAL EROSION: MORE ACID MEANS FEWER TEETH}

\section{Dr Thomas W. Boland}

General Dental Practitioner

Level 3, 64 Castlereagh Street, Sydney

The surfaces of the teeth are in a continuing state of flux throughout a lifetime. On contact with the tooth, a piece of grapefruit or a drink of orange juice will cause a demineralisation of the enamel or dentine surface. If no further acid attack occurs, the tooth can be remineralised over time by calcium and phosphate ions from the saliva. The balance of this dynamic ionic exchange can easily be upset resulting, for many patients, in irreversible and extensive tooth tissue loss (dental erosion) that may be difficult, if not impossible, to correct. As our knowledge of this form of tooth structure loss increases, there is a growing awareness of the complexity of the erosion process. This article examines the prevalence of dental erosion, the usual sources of acid responsible for it, other physiological factors that determine the impact of acid on the teeth, and ways of both managing and preventing dental erosion.

Dental erosion is defined as loss of dental hard tissue by a chemical process that does not involve bacteria. ${ }^{1}$ There is a perception among some dental clinicians that the occurrence and severity of dental erosion is increasing markedly. Epidemiological evidence now appears to confirm these observations. In a national survey of more than 2000 children in the United Kingdom, ${ }^{2}$ as many as 50 per cent of the five- and six-year-old patients studied displayed erosion of their first teeth, and 25 per cent were 